\title{
PENERAPAN ALGORITMA NAIVE BAYES DALAM MENENTUKAN KELAYAKAN NASABAH PADA KOPERASI SIMPAN PINJAM
}

\author{
Nurhayati $^{1}$, Indra ${ }^{2}$, Nuralamsyah Zulkarnaim ${ }^{3}$ \\ 1,2,3 Program Studi Informatika, Fakultas Teknik, Universitas Sulawesi Barat \\ Email: *1 nurhayatiaris04@gmail.com, ${ }^{2}$ indrauniq@ unsulbar.ac.id, ${ }^{3}$ nuralamsah@ unsulbar.ac.id
}

\begin{abstract}
Abstrak
Koperasi simpan pinjam menjadi salah satu alternatif bagi masyarakat untuk mendapatkan dana dalam upaya pemenuhan kebutuhan sehari -hari dan mengembangkan usaha. Pada proses menjalankan usaha kredit simpan pinjam koperasi adanya permasalahan yang umum terjadi seperti penunggakan pelunasan kredit.Melihat dari masalah tersebut, maka peneliti mengusulkan sebuah sistem untuk membantu pihak koperasi dalam menentukan kelayakan. Dengan model penilaian kredit yang tepat maka koperasi dapat mengevaluasi nasabah apakah layak mendapatkan kredit atau tidak, sehingga diharapkan dapat meminimalisir kerugian yang terjadi akibat penunggakan tersebut. Dari beberapa referensi yang terdahulu sistem ini akan menggunakan algoritma naive bayes sebagai metode penyelesaian, Dimana Algoritma Naive bayes dikenal sebagai teknik prediksi probabilitas yang dapat menganalisa variable-variable yang mempengaruhinya.
\end{abstract}

Kata kunci: - Prediksi Kelayakan, Koperasi Simpan Pinjam, Naive Bayes.

\begin{abstract}
Savings and loan cooperatives are an alternative for the community to obtain funds in an effort to meet their daily needs and develop a business. In the process of running a credit business, savings and loan cooperatives, common problems such as delinquency in credit repayments. Seeing this problem, researchers come from the system to assist the cooperative in determining eligibility. With the right product credit model, cooperatives can reach customers whether they deserve credit or not, so that it is expected to minimize losses arising from these losses. From several previous references, this system will use the Naive Bayes algorithm as a method of resolution, where the Naive Bayes Algorithm is known as a probability prediction technique that can analyze the variables that influence it.
\end{abstract}

Keywords: - Feasibility Prediction, Savings and Loans Cooperative, Naive Bayes.

\section{PENDAHULUAN}

Koperasi sebagai salah satu bentuk organisasi yang penting dalam meningkatkan pertumbuhan ekonomi. Koperasi simpan pinjam menjadi salah satu alternatif bagi masyarakat 
untuk mendapatkan dana dalam upaya memperbaiki taraf kehidupan, pemSenuhan kebutuhan sehari -hari dan mengembangkan usaha. Pada proses menjalankan usaha kredit simpan pinjam koperasi memiliki aturan yang sudah ditetapkan dalam menentukan calon nasabah. Aturan tersebut bertujuan untuk mengurangi adanya permasalahan seperti penunggakan dalam pelunasan cicilan.

Penunggakan terjadi saat nasabah yang telah diberi pinjaman tersebut tidak mau atau tidak mampu memenuhi janji yang telah dibuat dan disetujui antara kedussa belah pihak. dimana semakin banyaknya penunggakan dari waktu ke waktu dan sulit untuk ditagihkan, sementara kesederhanaan administrasi koperasi belum mampu melindungi koperasi dari kegagalan menagih hutang kenasabah. Dengan menerapkan dan membuktikan keberhasilan konsep kerja Algoritma naive bayes dalammenentukan nasabah yang layak menerima pinjaman diharapkan penelitian ini dapat digunakan sebagai referensi untuk bahan acuan bagi mahasiswa saat melakukan penelitian yang berkaitan dengan implementasi metode kerja algoritma Naive bayes.

\section{TINJAUAN PUSTAKA}

\subsection{Koperasi Simpan Pinjam (KSP)}

Koperasi simpan pinjam (KSP) merupakan salah satu bentuk lembaga finansial yang berperan penting dalam membantu meningkatkan taraf hidup masyarakat dengan cara menghimpun dana dan menyalurkannya dalam bentuk kredit atau pinjaman kepada masyarakat. Kredit sendiri merupakan kemampuan untuk melaksanakan suatu pembelian atau mengadakan suatu pinjaman dengan suatu janji, pembayarannya akan dilakukan dan ditangguhkan pada suatu jangka waktu yang disepakati (Kohler, 1983).

\subsection{Data Mining}

Data mining adalah proses yang memperkerjakan satu atau lebih teknik pembelajaran komputer (machine learning) untuk menganalisis dan mengekstraksi pengetahuan (knowledge) secara otomatis. Definisi lain diantaranya adalah pembelajaran berbasis induksi (inductionbased learning) adalah proses pembentukan definisi-definisi konsep umum yang dilakukan dengan cara mengobservasi contoh-contoh spesifik dari konsep-konsep yang akan dipelajari. Knowledge Discovery in Databases (KDD) adalah penerapan metode saintifik pada data mining. Dalam konteks ini data mining merupakan satu langkah dari proses KDD( DATA MINING:Data Mining Concepts And Techniques, 2013).

\subsection{Algoritma Naive bayes}

Bayesian classification adalah pengklasifikasian statistik yang dapat digunakan untuk memprediski probabilitas keanggotaan suatu class. Bayesian classification didasarkan pada teorema Bayes yang memiliki kemampuan klasifikasi serupa dengan decesion tree dan neural network. Bayesian classification terbukti memiliki akurasai dan kecepatan yang tinggi saat diaplikasikan ke dalam database dengan data yang besar. (Kusrini,2009).

\subsection{Pemrograman Python}

Python adalah bahasa pemrograman interpretatif multiguna. Tidak seperti bahasa lain yang susah untuk dibaca dan dipahami, python lebih menekankan pada keterbacaan kode agar lebih mudah untuk memahami sintaks. Hal ini membuat Python sangat mudah dipelajari baik untuk pemula maupun untuk yang sudah menguasai bahasa pemrograman lain.

Bahasa ini muncul pertama kali pada tahun 1991, dirancang oleh seorang bernama Guido van Rossum. Sampai saat ini Python masih dikembangkan oleh Python Software Foundation. Bahasa Python mendukung hampir semua sistem operasi, bahkan untuk sistem operasi Linux, hampir semua distronya sudah menyertakan Python di dalamnya. 


\section{METODE PENELITIAN}

Adapun Teknik pengumpulan data yang diterapkan pada penelitian ini yaitu:

\subsection{Pengamatan/Observasi}

Observasi merupakan teknik pengumpulan data dengan cara melakukan penelitian langsung pada obyek penelitian. Dalam hal ini, peneliti terjun secara langsung ke lapangan dengan tujuan memperoleh informasi tambahan maupun untuk mengetahui kebenaran informasi yang didapat dari subjek pada saat observasi.

\subsection{Wawancara}

Wawancara yaitu teknik pengumpulan data dengan mengadakan tanya jawab secara langsung dengan narasumber mengenai masalah masalah yang berhubungan dengan penelitian. Wawancara dilakukan dengan pihak koperasi terutama pimpinan koperasi, bagian survey lapangan atau bagian admin kredit yang terkait dalam prosedur pemberian kredit. Adapun data yang dikumpulkan dengan menggunakan metode ini mengenai prosedur pemberian kredit serta syarat - syarat atau kriteria nasabah yang dapat dinyatakan layak dalam pemberian pinjaman oleh koperasi.

\subsection{Dokumentasi}

Dokumentasi yaitu pengumpulan data dengan cara menyalin ulang dokumen pada Koperasi Simpan Pinjam "Berkat" Cabang Majene yang berkaitan dengan permasalahan. Seperti data nasabah yang sebelumnya telah dinyatakan layak oleh pihak koperasi.

\section{A. Flowchart Proses Algoritma Naive Bayes}

Untuk menjelaskan fungsi Algoritma Naive Bayes dalam memprediksi kelayakan yang dibuat maka akan digambarkan suatu rancangan Flowchart proses perhitungan secara menyeluruh pada gambar 2 berikut .

1) Flowchart Proses Algoritma Naive bayes 


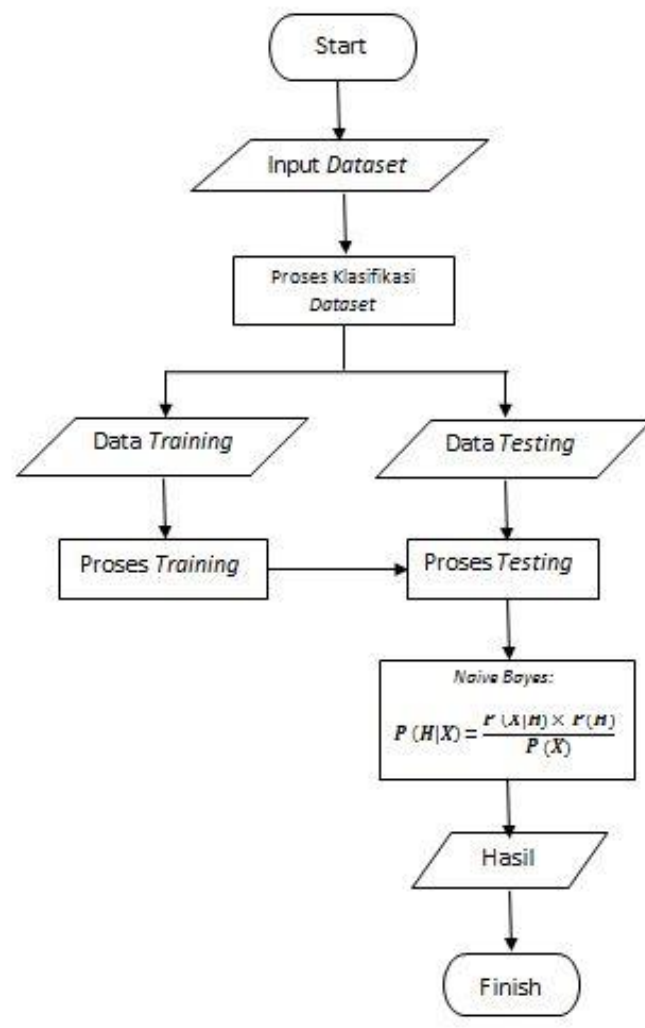

Gambar 2. Proses Algoritma Naive bayes

Dari rancangan proses Algoritma Naive Bayes diatas, telah disesuaikan dengan tahapan proses dari penerapan Algoritma menggunakan bahasa pemrograman python. Dimana langkah pertama yang dilakukan adalah menginput dataset yang diperoleh dari koperasi kemudian dataset tersebut akan diklasifikasikan menjadi data training dan data testing. Setelah data training diproses, selanjutnya pada bahasa pemrograman python akan dilakukan pemanggilan fungsi Naive bayes. Dimaksudkan untuk menghitung probabilitas dari data testing sehingga menghasilkan prediksi yang akan menjadi acuan dalam menentukan kelayakan nasabah.

\section{HASIL DAN PEMBAHASAN}

Hasil dari penelitian yang dilakukan penulis dengan judul Penerapan Algoritma Naive Bayes untuk memprediksi Kredit Macet Pada Koperasi Simpan Pinjam adalah sebagai berikut:

\section{A. Pengelompokkan Atribut}

Pengelompokkan attribut pada penelitian ini dikategorikan berdasarkan pekerjaan, agunan, penghasilan, nominal kredit dan jangka waktu. Attribut yang dimaksud dalam penelitian ini adalah kriteria-kriteria yang telah ditetapkan pihak koperasi dalam menentukan layak atau tidaknya calon nasabah untuk diberikan pinjaman.

Tabel 2. Attribut (kriteria-kriteria oleh pihak koperasi)

\begin{tabular}{|c|c|c|}
\hline Variabel & Atribut & Keterangan \\
\hline $\mathrm{X} 1$ & Pekerjaan & $\begin{array}{l}\text { PNS } \\
\text { Pensiunan } \\
\text { Wiraswasta }\end{array}$ \\
\hline $\mathrm{X} 2$ & Agunan & SK II \\
\hline
\end{tabular}




\begin{tabular}{|c|l|l|}
\hline & & SK III \\
& & SK IV \\
& & Sertifikat Tanah \\
& & BPKB Mobil \\
& & BPKB Motor \\
\hline \multirow{3}{*}{ X3 } & Penghasilan & $<2.000 .000$ (Rendah) \\
& & $>2.000 .000-5.000 .000$ (Cukup) \\
& & $>5.000 .000$ (Tinggi) \\
\hline & Nominal Kredit & $10.000 .000-25.000 .000$ (Rendah) \\
& $>25.000 .000-45.000 .000$ \\
& & (Sedang) \\
\hline \multirow{3}{*}{ X5 } & Jangka Waktu & $>45.000 .000-70.000 .000$ (Tinggi) \\
& & $1-12$ Bulan (Pendek ) \\
& & Lebih dari 36 Bulan (Panjang) \\
\hline
\end{tabular}

\section{B. Perhitungan Algoritma Naive Bayes}

Perhitungan manual dengan menggunakan algoritma Naive Bayes dapat menjadi acuan pembuktian terhadap beberapa sampel data mengenai tingkat akurasi kebenarannya. Dengan mengambil 155 data pada koperasi dari hasil dokumentasi pengumpulan data, dimana data tersebut digunakan sebagai data training dan data testing untuk penentuan kelayakan nasabah. Berikut adalah sebagian data nasabah dari 155 data pada koperasi.

Tabel 3. Data nasabah tahun 2019 dari koperasi

\begin{tabular}{|c|c|c|c|c|c|c|c|}
\hline NO & PEKERJAAN & AGUNAN & PENGHASILAN & & SAR KREDIT & $\begin{array}{c}\text { JNK } \\
\text { WAKTU }\end{array}$ & KATEGORI \\
\hline 1 & PNS & SK III & Cukup & $\mathrm{R}_{\mathrm{I}}$ & 25.000 .000 & 36 & Layak \\
\hline 2 & PNS & SK III & Cukup & $\mathrm{R}_{1}$ & 35.000 .000 & 60 & Layak \\
\hline 3 & WIRASWASTA & $\begin{array}{l}\text { SERTIFIKAT } \\
\text { TANAH }\end{array}$ & Cukup & $\mathrm{R}_{1}$ & 35.000 .000 & 24 & Layak \\
\hline 4 & PNS & SK III & Cukup & $\mathrm{R}_{1}$ & 20.000 .000 & 36 & Layak \\
\hline 5 & PENSIUNAN & SK PENSIUN & Tinggi & $\mathrm{R}_{\mathrm{d}}$ & 30.000 .000 & 36 & Layak \\
\hline 6 & PNS & SK IV & Tinggi & $\mathrm{R}_{1}$ & 55.000 .000 & 36 & Layak \\
\hline 7 & PENSIUNAN & SK PENSIUN & Cukup & $\mathrm{R}_{\mathrm{d}}$ & 15.000 .000 & 24 & Layak \\
\hline 8 & PNS & SK II & Rendah & $\mathrm{R}_{1}$ & 20.000 .000 & 36 & Layak \\
\hline 9 & PNS & SK III & Cukup & $\mathrm{R}_{1}$ & 35.000 .000 & 24 & Layak \\
\hline 10 & PENSIUNAN & SK PENSIUN & Cukup & $\mathrm{R}_{1}$ & 20.000 .000 & 36 & Layak \\
\hline 11 & WIRASWASTA & BPKB MOTOR & Rendah & $\mathrm{R}_{\mathrm{J}}$ & 70.000 .000 & 36 & Tidak Layak \\
\hline 12 & WIRASWASTA & BPKB MOTOR & Rendah & $\mathrm{R}_{1}$ & 45.000 .000 & 24 & Tidak Layak \\
\hline 13 & PENSIUNAN & SK PENSIUN & Rendah & $\mathrm{R}_{1}$ & 40.000 .000 & 24 & Tidak Layak \\
\hline 14 & PNS & SK II & Rendah & $\mathrm{R}_{\mathrm{I}}$ & 20.000 .000 & 36 & Layak \\
\hline 15 & PNS & SK III & Cukup & $\mathrm{R}_{\mathrm{l}}$ & 11.000 .000 & 18 & Layak \\
\hline
\end{tabular}

Tabel 4. Data Testing

\begin{tabular}{|c|ccccccc|}
\hline NO & PEKERJAAN & AGUNAN & PENGHASILAN & BESAR KREDIT & JNK WAKTU & KATEGORI \\
\hline 1 & WIRASWASTA & BPKB MOTOR & Rendah & Rp 55.000 .000 & 36 & ? \\
\hline
\end{tabular}


Perhitungan Algoritma Naive Bayes pada tabel sebagai berikut:

1. Menghitung jumlah class/label untuk data yang layak dan tidak layak

$\mathrm{P}(\mathrm{H}=$ Layak $)=\frac{102 \text { (Jumlah data nasabah yang "Layak"pada data training) }}{155 \text { (r) }}$

$\mathrm{P}(\mathrm{H}=$ Tidak Layak $)=\frac{53 \text { (Jumlah data nasabah " Tidak Layak"pada data training })}{155(\text { Jumlah keseluruhan data nasabah data training })}$

2. Menghitung jumlah kasus yang sama dengan class atau Mencari nilai probabilitas pada tiap atribut.

Layak:

$$
\begin{aligned}
& \mathrm{P}(\mathrm{X} 1=\text { WIRASWASTA } \mid \mathrm{H}=\text { Layak })=\frac{7 \text { (Jumlah data "Wiraswasta" kategori "Layak") }}{102(\mathrm{Jumlah} \text { data "Layak") }} \\
& \mathrm{P}(\mathrm{X} 2=\mathrm{BPKB} \text { MOTOR } \mid \mathrm{H}=\text { Layak })=\frac{2 \text { (Jumlah data "BPKB MOTOR" kategori "Layak") }}{102 \text { (Jumlah data "Layak") }} \\
& \mathrm{P}(\mathrm{X} 3=\text { Rendah } \mid \mathrm{H}=\text { Layak })=\frac{24 \text { (Jumlah data "Rendah" kategori "Layak") }}{102(\mathrm{Jumlah} \text { data "Layak") }} \\
& \mathrm{P}(\mathrm{X} 4=\text { Tinggi } \mid \mathrm{H}=\text { Layak })=\frac{8 \text { (Jumlah data "Tinggi" kategori "Layak") }}{102 \text { (Jumlah data "Layak") }} \\
& \mathrm{P}(\mathrm{X} 5=\text { Menengah } \mid \mathrm{H}=\text { Layak })=\frac{\text { 96(Jumlah data "Menengah" kategori "Layak") }}{102(\text { Jumlah data "Layak") }}
\end{aligned}
$$

Tidak layak:

$$
\begin{aligned}
& \mathrm{P}(\mathrm{X} 1=\text { WIRASWASTA } \mid \mathrm{H}=\mathrm{TL})=\frac{26(\mathrm{Jumlah} \text { data "Wiraswasta" kategori "Tidak Layak") }}{53(\mathrm{Jumlah} \text { data "Tidak Layak") }} \\
& \mathrm{P}(\mathrm{X} 2=\mathrm{BPKB} \text { MOTOR } \mid \mathrm{H}=\mathrm{TL}) \quad= \\
& 24 \text { (Jumlah data "Wiraswasta" kategori "Tidak Layak") } \\
& 53 \text { (Jumlah data "Tidak Layak") } \\
& \mathrm{P}(\mathrm{X} 3=\text { Rendah } \mid \text { Penghasilan } \mid \mathrm{H}=\mathrm{TL})=\frac{53 \text { (Jumlah data "Rendah" kategori "Tidak Layak") }}{53 \text { (Jumlah data "Tidak Layak") }} \\
& \mathrm{P}(\mathrm{X} 4=\text { Tinggi } \mid \mathrm{H}=\mathrm{TL}) \quad=\frac{32(\mathrm{Jumlah} \text { data "Tinggi” kategori "Tidak Layak") }}{53(\mathrm{Jumlah} \text { data "Tidak Layak") }} \\
& \mathrm{P}(\mathrm{X} 5=\text { Menengah } \mid \mathrm{H}=\mathrm{TL})=\frac{46 \text { (Jumlah data "Menengah" kategori "Tidak Layak") }}{53 \text { (Jumlah data "Tidak Layak") }}
\end{aligned}
$$

3. Membandingkan hasil Probabilitas tiap kelas

Kalikan semua hasil variabel layak dan tidak layak

$$
\begin{aligned}
& \mathrm{P}(\mathrm{X} \mid \mathrm{H}=\text { Layak }) \times \mathrm{P}(\mathrm{H}=\text { Layak })= \mathrm{P}(\mathrm{X} 1=\text { WIRASWASTA } \mid \mathrm{H}=\text { Layak }) \times \\
& \mathrm{P}(\mathrm{X} 2=\text { BPKB MOTOR } \mid \mathrm{H}=\text { Layak }) \times \\
& \mathrm{P}(\mathrm{X} 3=\text { Rendah } \mid \mathrm{H}=\text { Layak }) \times \\
& \mathrm{P}(\mathrm{X} 4=\text { Tinggi } \mid \mathrm{H}=\text { Layak }) \times \\
& \mathrm{P}(\mathrm{X} 5=\text { Menengah } \mid \mathrm{H}=\text { Layak }) \times \mathrm{P}(\mathrm{H}=\text { Layak }) \\
&=\frac{7}{102} \times \frac{2}{102} \times \frac{24}{102} \times \frac{8}{102} \times \frac{96}{102} \times \frac{102}{155} \\
&= 0,00001538(\text { Hasil perkalian variabel "Layak" }) \\
& \mathrm{P}(\mathrm{X} \mid \mathrm{H}=\text { Tidak Layak }) \times \mathrm{P}(\mathrm{H}=\text { Tidak Layak })=\mathrm{P}(\mathrm{X} 1=\text { WIRASWASTA } \mid \mathrm{H}=\text { TidakLayak }) \times \\
& \mathrm{P}(\mathrm{X} 2=\text { BPKB MOTOR } \mid \mathrm{H}=\text { Tidak Layak }) \times \mathrm{P} \\
&(\mathrm{X} 3=\text { Rendah } \mid \mathrm{H}=\text { Tidak Layak }) \times \\
& \mathrm{P}(\mathrm{X} 4=\text { Tinggi } \mid \mathrm{H}=\text { Tidak Layak }) \times \\
& \mathrm{P}(\mathrm{X} 5=\text { Menengah } \mid \mathrm{H}=\text { Tidak Layak }) \times \\
& \mathrm{P}(\mathrm{H}=\text { Tidak Layak }) \\
&=\frac{26}{53} \times \frac{24}{53} \times \frac{53}{53} \times \frac{32}{53} \times \frac{46}{53} \times \frac{53}{155}
\end{aligned}
$$


$=0,03980458$ (Hasil perkalian variable "tidak layak")

Bandingkan hasil perkalian dari variabel layak dan tidak layak. Hasil yang diperoleh dari perhitungan manual data testing menunjukan bahwa nilai probabilitas tertinggi terdapat pada kelas $(\mathrm{P}=$ Tidak Layak) sehingga dapat disimpulkan bahwa status calon nasabah tersebut dinyatakan Tidak layak.

\section{Pengujian}

Setelah penjelasan pada halaman sebelumnya tentang perhitungan Algoritma Naive Bayes secara manual maka selanjutnya akan dilakukan pengujian peforma Algoritma Naive bayes dengan bahasa pemrograman Python.

1. Perhitungan Akurasi

$\begin{array}{rrrrr} & \text { precision } & \text { recall } & \text { fl-score } & \text { support } \\ \text { layak } & 0.89 & 1.00 & 0.94 & 8 \\ \text { tidak layak } & 1.00 & 0.50 & 0.67 & 2 \\ \text { accuracy } & & & 0.90 & 10 \\ \text { macro avg } & 0.94 & 0.75 & 0.80 & 10 \\ \text { weighted avg } & 0.91 & 0.90 & 0.89 & 10\end{array}$

Dari pengujian tahap pertama diperoleh hasil bahwa, dari 10 data testing di atas diperoleh hasil dimana terdapat 2 data yang Failed saat pengujian.Akurasi yang diperoleh pada percobaan ini sebesar 0,90 atau sebesar $90 \%$.

$\begin{array}{rrrrr} & \text { precision } & \text { recall } & \text { fl-score } & \text { support } \\ \text { layak } & 0.93 & 1.00 & 0.97 & 14 \\ \text { tidak layak } & 1.00 & 0.86 & 0.92 & 7 \\ \text { accuracy } & & & & \\ \text { macro avg } & 0.97 & 0.93 & 0.95 & 21 \\ \text { weighted avg } & 0.96 & 0.95 & 0.95 & 21\end{array}$

Pada tahap pengujian kedua diperoleh hasil bahwa, dari 20 data testing di atas diperoleh hasil dimana terdapat 7 data yang Failed saat pengujian.Akurasi yang diperoleh pada percobaan ini sebesar 0,95 atau sebesar $95 \%$.

$\begin{array}{rrrrr} & \text { precision } & \text { recall } & \text { fl-score } & \text { support } \\ \text { layak } & 1.00 & 0.95 & 0.98 & 22 \\ \text { tidak layak } & 0.88 & 1.00 & 0.93 & 7 \\ \text { accuracy } & & & & \\ \text { macro avg } & 0.94 & 0.98 & 0.97 & 29 \\ \text { weighted avg } & 0.97 & 0.97 & 0.97 & 29\end{array}$


Pada tahap pengujian ketiga diperoleh hasil bahwa, dari 30 data testing di atas diperoleh hasil dimana terdapat 7 data yang Failed saat pengujian.Akurasi yang diperoleh pada percobaan ini sebesar 0,97 atau sebesar $97 \%$.

\section{KESIMPULAN}

Berdasarkan hasil yang diperoleh dalam pengujian peforma penerapan Algoritma Naive Bayes menggunakan bahasa pemrograman Python, dengan melakukan tahap pengujian sebanyak 3 kali terhadap 155 data training. Pada pengujian pertama diperoleh nilai akurasi sebesar $90 \%$ dari 10 data testing, kemudian untuk pengujian kedua diperoleh niai akurasi sebesar $95 \%$ dari 20 data testing, dan untuk pengujian ketiga diperoleh $97 \%$ dari 30 data testing. Dimana, jika dirata-ratakan didapatkan $94 \%$ dari semua hasil akurasi pengujian . Maka penelitian dengan judul "PENERAPAN ALGORITMA NAIVE BAYES DALAM MENENTUKAN KELAYAKAN NASABAH PADA KOPERASI SIMPAN PINJAM" dapat dinyatakan berhasil.

Untuk meningkatkan kinerja dan menyempurnakan penelitian yang telah dibuat, peneliti memberikan saran sebagai berikut :

1. Untuk pengembangan penelitian ini dapat menggunakan metode yang berbeda atau Algoritma lainnya.

2. Penambahan attribut atau kriteria nasabah sesuai dengan yang ditetapkan pihak koperasi .

3. Supaya hasil yang didapat lebih akurat sebaiknya menggunakan data yang lebih banyak lagi.

4. Peneliti selanjutnya dapat melakukan pengembangan dengan membuat tampilan aplikasi.

\section{REFERENSI}

[1] Yuli Mardi (2007). Data Mining :Klasifikasi Mengunakan Algoritma C4.5

[2] Angga Ginanjar Mabrur[1], Riani Lubis[2]. (2012), Penerapan Data MiningUntuk Memprediksi Kriteria Nasabah Kredit

[3] Mei Lestari (2014). Penerapan Algoritma Klasifikasi Nearest Neighbor (K-Nn) Untuk Mendeteksi Penyakit Jantung

[4] Dedy Ahmad Kurniawan1), Danny Kriestanto2). 19 Penerapan Naïve Bayes Untuk Prediksi Kelayakan Kredit

[5] Hari Wiyana1, Sigit Kurniawan2, Toni S. Ali3 (2018). Memprediksi Transaksi Nasabah Pada Koperas Simpan Pinjam Pt. Asuransi Staco Mandiri Dengan Algoritma C4.5

[6] Iqbal Taufiq Ahmad Nur1, Nanang Yudi Setiawan2, Fitra Abdurrachman Bachtiar3lczko, M. (2018). Prediksi Kredit Macet Berdasarkan Preferensi Nasabah Menggunakan Metode Klasifikasi C4.5 pada Koperasi Simpan Pinjam Mitra Raya Wates 
[7] Wakhidatul Fauziah dan Said Sunardiyo. (2015). Penerapan Metode Simple Additive Weighting dalam Sistem Pendukung Keputusan Kelayakan Laboratorium Komputer SMP dan SMA Negeri untuk Unit Pelaksana Teknis Dinas Pendidikan Kecamatan Sukorejo.

[8] Henny Leidiyana. (2013). Penerapan Algoritma K-Nearest Neighbor Untuk Penentuan Resiko Kredit Kepemilikan Kendaraan Bemotor

[9] Tati Mardiana. (2017). Penerapan Algoritma Topsis Dalam Sistem Pendukung Keputusan Pemberian PinjamanPada Koperasi Karyawan.

[10]Jiawei Han. (2012). Data Mining Concepts and Techniques,Third Edition. United States of America 